\title{
Effect of Extracorporeal Membrane Oxygenation on Cerebral Blood Flow and Cerebral Oxygen Metabolism in Newborn Sheep
}

\author{
BILLIE LOU SHORT, L. KYLE WALKER, CHRISTINE A. GLEASON, M. DOUGLAS JONES, JR, \\ AND RICHARD J. TRAYSTMAN \\ The George Washington University, Department of Pediatrics and The Children's Hospital National Medical \\ Center, Washington, D.C. 20010 [B.L.S.] and the Johns Hopkins Medical Institutions, The Department of \\ Pediatrics [C.A.G., M.D.J.J and the Department of Anesthesiology and Critical Care Medicine [L.K.W., R.J.T.].
} Baltimore, Maryland 21205

\begin{abstract}
Extracorporeal membrane oxygenation (ECMO) supplies respiratory support to term or near-term infants with respiratory failure. Although infants requiring this therapy may have already sustained significant hypoxia and/or ischemia predisposing them to neurologic injury, the high incidence of neuroimaging abnormalities in the ECMO population raises concerns about the additional neurologic risk associated with the ECMO procedure itself. Our study was undertaken to evaluate the effects of ECMO on the normal neonatal cerebral circulation. Thirteen newborn lambs (1-7 d of age) were placed on normothermic venoarterial ECMO using a silicone membrane oxygenator and roller occlusion pump. Regional brain blood flows, cerebral oxygen consumption, fractional oxygen extraction, and oxygen transport were determined 30 and 120 min after initiation of ECMO. Neither cerebral blood flow (baseline, $60.2 \pm 23.6 ; 30 \mathrm{~min}, 56.1 \pm 18.1 ; 120$ min $56.1 \pm 12.9 \mathrm{~mL} / 100 \mathrm{~g} / \mathrm{min}$ ) nor oxygen metabolism (cerebral oxygen consumption: baseline, $4.48 \pm 1.48$; 30 $\min , 3.86 \pm 1.53 ; 120 \mathrm{~min}, 4.10 \pm 1.32 \mathrm{~mL} / 100 \mathrm{~g} / \mathrm{min}$ and oxygen extraction: baseline, $0.52 \pm 0.09 ; 30 \mathrm{~min}, 0.47 \pm$ $0.14 ; 120 \mathrm{~min}, 0.46 \pm 0.14 \mathrm{~mL} / 100 \mathrm{~g} / \mathrm{min}$ ) changed after the initiation of ECMO. Regional and left/right blood flow differences were not noted. These findings suggest that in healthy newborn lambs, initiation of ECMO does not alter cerebral blood flow or oxygen metabolism. (Pediatr Res 28: 50-53, 1990)
\end{abstract}

\section{Abbreviations}

ECMO, extracorporeal membrane oxygenation CBF, cerebral blood fow

ECMO supplies respiratory support in term or near-term infants who do not respond to conventional medical management for severe cardiopulmonary failure. Although the average national ECMO survival rate is over $80 \%$, with short-term followup studies indicating that the majority of these infants are normal, there are concerns for the risks associated with the procedure (1-6). The chief concern is that the procedure causes or worsens damage to the CNS. Forty-seven percent of the first 207 infants treated with ECMO at Children's National Medical

Received November 10, 1989; accepted March 16, 1990.

Correspondence and reprint requests: Billie Lou Short, M.D., Director ECMO Program, Children's National Medical Center, Department of Neonatology, 11] Michigan Ave, N.W., Washington, D.C. 20010
Center in Washington, DC had abnormal findings on neuroimaging studies (3). Twenty-three percent of these lesions were considered major. Although all of these lesions could theoretically be attributed to pre-ECMO hypoxia and asphyxia, it is also possible that they result from the ECMO procedure itself. Some of the risks of ECMO, like prolonged heparinization and ligation of the carotid artery and jugular vein, are of immediate and real concern, whereas others, like possible alterations in the physiologic responses of cerebral vessels from decreased pulsatility of arterial inflow or from chemical compounds released from the ECMO circuitry, are less well defined (1-6).

Adding to these concerns are data from a previous study in which we found that institution of ECMO results in an immediate and pronounced increase in CBF velocity (2). This finding could be explained either by acute vasoconstriction or, more likely, by a sudden increase in CBF. Our present experiments were therefore designed to test the hypothesis that institution of ECMO alone, in the absence of alteration of any other variables, is associated with alterations in CBF and/or cerebral oxygen consumption.

\section{MATERIALS AND METHODS}

Subjects. Eighteen anesthetized lambs of mixed breed 1 to $7 \mathrm{~d}$ of age were used for these experiments.

Surgical procedures. Lambs were anesthetized with pentobarbital $(7-18 \mathrm{mg} / \mathrm{kg})$ before surgery, and then maintained on a pentobarbital drip $(5 \mathrm{mg} / \mathrm{kg} / \mathrm{h}$ ) for the remainder of the surgery and the experiment. Catheters were placed into the right femoral artery for continuous blood pressure monitoring and the right femoral vein for administration of i.v. fluids and medications. The microsphere reference catheter was placed into the left lingual artery. To gain access to the superior sagittal sinus, the skull was entered in the midline approximately $1 \mathrm{~cm}$ anterior to the lambda. The sagittal sinus was identified, and the overlying dura was punctured with a 19-gauge needle. The catheter was placed proximal to the confluence of sinuses to obtain sagittal sinus blood for analysis of cerebral venous blood gases and pressure monitoring. The ECMO venous catheter (14-16 Fr, Electro-Catheter Corp., Rahway, NJ, or 18 Fr, Argyle/Sherwood, St. Louis, MO) was placed into the right jugular vein and advanced into the right atrium. The ECMO arterial catheter (8$12 \mathrm{Fr}$, Argyle/Sherwood) was placed $2 \mathrm{~cm}$ above the aortic valve. Five animals had additional microsphere withdrawal catheters placed in the right and left axillary arteries to validate microsphere injection on ECMO.

Microsphere validation. Five animals with microsphere withdrawal catheters placed in the left lingual and right and left 
axillary arteries were studied to validate the appropriate microsphere injection site while on ECMO. Animals were anesthetized, intubated, and ventilated using Harvard Pump Respirator (Harvard Apparatus, Dover, MA), and all catheters except the ECMO catheters were placed. Before placement of the ECMO catheters, the animal was heparinized with a bolus of $200 \mathrm{U} / \mathrm{kg}$ of sodium heparin $(1000 \mathrm{U} / \mathrm{mL}$, Porcine heparin, Elkins-Sinns, Inc., Cherry Hill, NJ) and maintained on a heparin drip of 35 to $50 \mathrm{U} / \mathrm{kg} / \mathrm{h}$ to maintain an activated clotting time (Hemachron 400 , International Technidyne, Edison, NJ) of $250-280$ s throughout the study period. After stabilization, two baseline measurements were taken $30 \mathrm{~min}$ apart. Animals were placed on $150 \mathrm{~mL} / \mathrm{kg} /$ min of ECMO flow by increasing the ECMO flow by $50-\mathrm{mL}$ increments over a 15 -min period. Measurements were taken at 30 and $120 \mathrm{~min}$ after the initiation of $150 \mathrm{~mL} / \mathrm{kg} / \mathrm{min}$ of ECMO flow. At all study periods, microspheres were injected into the ECMO arterial catheter at the port in the connection of the catheter to the ECMO circuit (approximately $10 \mathrm{~cm}$ from the insertion of the catheter into the carotid artery). Simultaneous withdrawals from the left lingual and left and right axillary arteries were compared to determine if equal mixing of the mictospheres occurred after injection into the ECMO arterial catheter and to show that $150 \mathrm{~mL} / \mathrm{kg} / \mathrm{min}$ of ECMO flow did not create significant streaming of the injected microspheres.

Experimental protocol. Thirteen animals were anesthetized and instrumented as above. After stabilization, baseline measurements were taken before initiation of ECMO. Measurements were taken at 30 and 120 min after initiation of $150 \mathrm{~mL} / \mathrm{kg} / \mathrm{min}$ of ECMO flow. Animals were killed at the end of the study with an overdose of pentobarbital (sodium pentobarbital, $65 \mathrm{mg} / \mathrm{mL}$, Harvey Laboratories, Inc., Philadelphia, PA) and KCl (Fisher Scientific, Fair Lawn, NJ). Catheter placement was verified at autopsy and the brain was removed for microsphere analysis.

The ECMO procedure. Venoarterial bypass was used for the study using a standard venous catheter, a 50 -mL venous reservoir (R50-1, Sci Med, Life Systems Inc., Minneapolis, MN), a roller occlusion pump (Picker International, Mayfield Village, $\mathrm{OH}$ ) a Sci Med $\left(0.8 \mathrm{M}^{2}, 0800-2 \mathrm{~A}\right)$ silicone membrane oxygenator, a heat exchanger (Omnitherm Heat Exchanger, P-7-14, Sci Med), and the return arterial catheter. Routine flows required to oxygenate the newborn human infant range from 120 to $150 \mathrm{~mL} /$ $\mathrm{kg} / \mathrm{min}$, representing approximately $60 \%$ of their cardiac output (200 to $300 \mathrm{~mL} / \mathrm{kg}$ ). Because the $1-$ to $7-\mathrm{d}$ lamb has a similar cardiac output (7), $150 \mathrm{~mL} / \mathrm{kg} / \mathrm{min}$ was chosen as the ECMO flow rate to be studied. Membrane blood gases were kept as in the clinical state with fraction of inspired oxygen 1.00 , resulting in a postmembrane $\mathrm{PaO}_{2}$ of 350 to 450 torr.

Physiologic measurements. CBF was measured using the radiolabeled microsphere technique (8). Radioactive microspheres of $15-\mu \mathrm{M}$ diameter (approximately $1.4 \times 10^{6}$ microspheres), labeled with ${ }^{153} \mathrm{Gd},{ }^{114} \mathrm{In},{ }^{113} \mathrm{Sn},{ }^{103} \mathrm{Ru},{ }^{95} \mathrm{Nb}$, and ${ }^{46} \mathrm{Sc}$ (DuPont, Boston, MA) were randomly chosen and $0.4 \mathrm{~mL}$ injected over $45 \mathrm{~s}$ into the ECMO arterial catheter. Simultaneously, a reference blood sample was withdrawn from the lingual artery at a rate of $2.47 \mathrm{~mL} / \mathrm{min}$ with a calibrated syringe pump (Harvard Apparatus). The withdrawal of the reference sample began $10 \mathrm{~s}$ before the injection and continued for $60 \mathrm{~s}$ after the injection was completed. Tissue and reference blood samples were counted in a deep well gamma scintillation counter (Packard Instrument Co., Inc, Downers Grove, IL). Blood flow was calculated as the product of tissue counts times the reference withdrawal rate divided by the counts in the reference blood sample. Flows were then normalized to $100 \mathrm{~g}$ of tissue wt. Blood flows were determined for the total brain, right and left hemispheres, brainstem, caudate, and cerebellum. All reference blood and tissue samples contained more than 400 microspheres.

Mean arterial pressure, pulse pressure, sagittal sinus pressure, arterial and venous $\mathrm{pH}, \mathrm{PCO}_{2}, \mathrm{PO}_{2}$, saturation, and $\mathrm{Hb}$ were measured at each study period. Samples for oxygen saturations and $\mathrm{Hb}$ were taken immediately before the injection of the
Table 1. $C B F(\mathrm{~mL} / 100 \mathrm{~g} / \mathrm{min})$ as measured using three arterial reference sites*

\begin{tabular}{cccc}
\hline & \multicolumn{3}{c}{ Arterial reference site } \\
\cline { 2 - 4 } & $\begin{array}{c}\text { Right } \\
\text { axillary }\end{array}$ & $\begin{array}{c}\text { Left } \\
\text { axillary }\end{array}$ & Lingual \\
\hline Baseline & $65.6 \pm 19.3$ & $67.1 \pm 14.0$ & $67.6 \pm 18.6$ \\
$30 \mathrm{~min}^{\dagger}$ & $50.3 \pm 12.4$ & $48.1 \pm 13.6$ & $50.0 \pm 10.1$ \\
$120 \mathrm{~min}^{\dagger}$ & $46.1 \pm 11.6$ & $48.1 \pm 12.2$ & $50.0 \pm 7.6$ \\
\hline
\end{tabular}

* Note: Microspheres injected into the ECMO arterial catheter. Data displayed as mean $\pm \mathrm{SD}, n=5$.

$\uparrow$ Time on ECMO.

Table 2. Cardiovascular and arterial blood gas variables before and during $E C M O^{*}$

\begin{tabular}{lccc}
\hline & \multicolumn{3}{c}{ Time on ECMO (min) } \\
\cline { 5 - 5 } \cline { 4 - 5 } & Baseline & 30 & 120 \\
\hline MAP (mm Hg) & $73 \pm 13$ & $68 \pm 11$ & $66 \pm 12$ \\
Pulse pressure (mm Hg) & $57 \pm 14$ & $27 \pm 13 \dagger$ & $37 \pm 15 \dagger$ \\
Sagittal sinus pressure $(\mathrm{mm} \mathrm{Hg})$ & $5 \pm 2$ & $4 \pm 2$ & $4 \pm 1$ \\
$\mathrm{pH}$ & $7.37 \pm .05$ & $7.40 \pm .01$ & $7.40 \pm .01$ \\
$\mathrm{PaCO}_{2}$ (torr) & $34 \pm 2$ & $36 \pm 3$ & $34 \pm 4$ \\
$\mathrm{PaO}_{2}$ (torr) & $98 \pm 25$ & $361 \pm 77 \dagger$ & $332 \pm 70 \dagger$ \\
$\mathrm{Hb}(\mathrm{g} / \mathrm{dL})$ & $11.3 \pm 1.5$ & $10.0 \pm 1.0$ & $11.0 \pm 2.0$ \\
\hline
\end{tabular}

* Values displayed as mean $\pm \mathrm{SD}, n=13$. MAP, mean arterial pressure; $\mathrm{PaCO}_{2}$, arterial $\mathrm{CO}_{2}$ tension; $\mathrm{PaO}_{2}$, arterial $\mathrm{O}_{2}$ tension.

$\dagger p<0.05$, values compared to baseline.

microspheres. Measurements were made using the Hemoximeter OSM2 (Radiometer, Cleveland, $\mathrm{OH}$ ) calibrated for lamb's blood. $\mathrm{PaO}_{2}, \mathrm{PaCO}_{2}$, and $\mathrm{pH}$ were measured at $39.5^{\circ} \mathrm{C}$ using the Radiometer ABL 30 . Blood pressures and heart rate were continuously monitored (Gould Instruments, Omand, CA).

Calculated values and data analysis. Cerebral oxygen consumption was calculated by multiplying blood flow to the hemispheres by the cerebral arteriovenous $\mathrm{O}_{2}$ content difference. Cerebral oxygen transport was calculated as the product of CBF times arterial oxygen content. Cerebral fractional oxygen extraction was calculated as the ratio of cerebral oxygen consumption to cerebral oxygen transport.

Differences in study variables between baseline and ECMO measurements were analyzed using repeated measures analysis of variance with statistical significance defined as $p<0.05$. Significant differences found were analyzed with Newman-Keuls.

\section{RESULTS}

Validation studies did not show a significant difference in brain blood flow measurements from the three reference sites, indicating that the injection of microspheres into the ECMO arterial catheter placed in the carotid artery, with ECMO flows at rates of $150 \mathrm{~mL} / \mathrm{kg} / \mathrm{min}$ resulted in good mixing of microspheres (Table 1). The reference catheter used for the remaining studies was the lingual arterial catheter.

Physiologic variables are shown in Table 2 . There was no significant change in mean arterial blood pressure, sagittal sinus pressure, or $\mathrm{Hb}$ after 30 or $120 \mathrm{~min}$ of ECMO. Pulse pressure decreased by $53 \%$ after $30 \mathrm{~min}$ of ECMO and remained low (66\% of baseline) after $120 \mathrm{~min}$ of ECMO. Arterial $\mathrm{PaO}_{2}$ increased significantly on ECMO, because the fraction of inspired oxygen administered to the membrane lung was 1,00 .

Initiation of venoarterial ECMO at $150 \mathrm{~mL} / \mathrm{kg} / \mathrm{min}$ flow had no immediate $(30 \mathrm{~min})$ or delayed $(120 \mathrm{~min})$ effect on CBF (Table 3) or oxygen consumption (Fig. I) in healthy newborn lambs. Cerebral oxygen metabolism before and during ECMO is shown in Figure 1. There was no change in fractional oxygen extraction or oxygen transport.

Regional brain blood flows are depicted in Table 2 and Figure 